patient says that three months ago he first passed small clots of blood mixed with slime, unaccompanied by a motion proper; when he did succeed in passing a motion, he noticed that it was flat, tape-like, generally with a smear of blood down one side. For the last two months, however, the motions have been without form. He has lost flesh markedly for the last two months. He had inflammation of the lungs nine years ago, and kidney trouble six years since, which lasted a week. Six months ago he was troubled with rheumatic pains in the right shoulder, which have not left him. His father died at seventy-five years of age, and his mother at seventy-eight, having had twenty-three children. No history of carcinoma anywhere. On the 24th Mr. Bloxam performed colotomy by means of an incision four inches long, the centre of which corresponded to the centre of a line drawn vertically from the crest of the ilium to the last rib, half an inch behind the middle point of a line connecting the anterior, superior, and posterior spines of the ilium. The direction of the incision was obliquely transverse. A search with the fingers in the abdominal fat readily brought the colon to the orifice of the wound, and it was then secured and opened in the usual manner. Drainagetubes were inserted above and below, and the ends of the wound sewn up and dressed with a simple pad of antiseptic tow and a bandage. The operation was followed by a good deal of collapse. A considerable amount of fæces escaped during the night.--29th: The temperature has been at $100^{\circ}$ yesterday and to-day, and the patient looks weak and exhausted.-Feb. 4th: The patient looks much better to-day, but his temperature is still about $100^{\circ}$. The wound has a healthy appearance, but the mucous membrane shows a tendency to protrude. - 20th: He has no pain at present, and sleeps well. Appetite improving. The patient was discharged on the $25 \mathrm{th}$, very much better in health and comfort.

\section{SUSSEX COUNTY HOSPITAL.}

CASE OF RECOVERY AFTER SWALLOWING A FLUID OUNCE AND A HALF OF COMMIRRCTAL HYDROCHLORIC ACID. (Under the care of Dr. H. Ross.)

For the following notes we are indebted to Dr. Robert Black, house-surgeon.

George $\mathrm{B}-$ - a man, aged thirty-nine, was brought to the hospital reported to have swallowed a dose of hydrochloric acid. It appeared that he had lately become melancholic, and had attempted suicide by laudanum four days previously, but was fortunately discovered and the poison taken from him. On the day of admission he purchased an ounce and a half of " spirits of salt," which he sent for in a small gallipot; he then filled an ounce and a half bottle with the acid and drank the whole of it. He was seen about ten minutes afterwards by Dr. Harris Ross, who at once administered some calcined magnesia and recommended his removal to the hospital.

On admission he was very pale and much collapsed. There was much retching, and he vomited a quantity of dark, blood-stained fluid with a peculiar almost aromatic smell. There was a well-marked red line at the back of the hard palate, where the acid had first come in contact with it He complained of no pain and no tenderness at the epigastrium. He was ordered some carbonate of potash and borax with Battley's solution of opium, but continued to vomit dark blood-stained fluid with small shreds of membrane.

May 4th.- The man has been quite free from pain and can swallow well, but is still sick from time to time. The bowels have acted without aperient, and the motions contain a little blood. A white membrane has formed on the dorsum of the tongue, and is slowly peeling off. He has now a good healthy colour in his cheeks, and presents a tranquil, comfortable appearance, and sleeps well all night. The temperature has been $99.5^{\circ}$ until to-day, and is now normal.

10th.-The patient has been up for two days, and appears perfectly well. There is no pain, no difficulty in deglutition, and the evacuations contain no blood. There has never been any marked constipation.

On the 12th he left tive hospital quite well. Dr. Ross ascertained from the chemist that the acid supplied was of the ordinary strength of the commercial crude hydrochloric acid; and it was conclusively proved that the fall amount above mentioned was taken.

\section{CARDIFF INFIRMARY}

A CASE OF CYSTIC GOITRE TREATED BY " SHELLING OUT." (Under the care of Dr. C. T. VACHELL.)

We are indebted for the following notes to Mr. William Duff.

Annie $\mathrm{Z}-$, aged twenty-three, married, was admitted on July 23rd, 1885, suffering from a tumour on the right side of the neck. She had enjoyed good health until five years ago, shortly after marriage, when a swelling commenced to form over the right side of the thyroid gland and continued slowly and persistently to enlarge. She had one child a year and a half ago, but neither pregnancy nor lactation seemed to influence the growth. On admission a tumour about the size of a cocoa-nut occupied the position of the right lobe of the thyroid gland, and passed some what over to the left of the middle line of the neck. The skin, with a few enlarged subcutaneous veins, was freely movable over the swelling, which moved with the trachea in the act of swallowing. Fluctuation could be felt all over it, more distinct in some parts than others. Neither breathing nor swallowing was seriously interfered with. About three weeks before admission a teacupful of bloody serous fluid was withdrawn by a trocar and cannula, and the tumour was considerably reduced in size, but reaccumulation took place in a day or two. By August 11th the tumour had attained a larger size than ever, the circumference of the neck being $17 \frac{3}{4}$ in. The patient was informed that if the tumour remained serious results might ensue, and she consented to an operation.

Ether having been administered, Dr. Vachell proceeded, on Aug. 12th, to remove the tumour under the carbolic spray. A vertical incision measuring about $2 \frac{1}{2}$ in. long was made through the skin over the most prominent part, and at once the surface of the tumour came into view the capsule of the gland, if present, having been so thinned by pressure as to present no difficulty. Up to this point very little hæmorrhage had occurred. Without much difficulty the tumour was now shelled out, but the hæmorrhage which commenced with this process, and continued throughout, was very profuse. Firm pressure was maintained by an assistant, the surface was mopped with very hot water mixed with tincture of iodine ( 1 in 20), and as bit by bit the surface was exposed all the bleeding points were ligatured. The edges were then brought together, and a drainage-tube inserted.

After the operation the progress was satisfactory. Some sickness in the afternoon and a troublesome cough led to considerable oozing, necessitating the dressing of the wound in the evening. The dressing was repeated the next day. On the 14th the tube was shortened, and on the 16th the stitches were removed. On the 19th boric dressing was substituted, and on the 24 th the patient left the infirmary.

The temperature rose on the evening of the day of the operation to $103.8^{\circ}$, and remained more or less febrile till the 19th. Probably this was due to an attack of bronchitis, from which she then suffered.

The tumour, which was irregularly ovoid in shape, measured 13 in. by 9 in., and weighed $20 \mathrm{oz}$. On being cut into, $9 \mathrm{oz}$. of dark sanguineous fluid escaped, similar to what had been removed by tapping, but darker. The walls varied from one-sixth of an inch to rather over half an inch in thickness, and consisted of material resembling heart muscular fibre in naked-eye appearance. The internal surface was much and deeply corrugated.

A Munifiche't Russian Nobleman.-Count Orloff Davidoff appears to be a most munificent benefactor to the sick poor of Russia. He recently gave $£ 24,000$ for the purpose of endowing a children's hospital dedicated to St. Olgar, in Moscow, which he had built at his own expense, besides buying a house for the purposes of the administration of the hospital, costing $£ 4000$. This noble foundation he has now further enriched with a gift of another $£ 24,000$. Dr. Chernoff, privat docent for children's diseases in the St. Petersburg Military Medical Arademy, has been appointed medical officer to the new institution, which is considered by the Russian medical press as an excellent choice. How much more satisfactory will it be to the munificent donor to be able to watch the success of his hospital than merely to leave part of his money in his will to be devoted to charity after his death. 